\title{
Is COPD associated with periodontal disease? A population-based study in Spain
}

This article was published in the following Dove Press journal:

International Journal of COPD

\author{
Ana Lopez-de-Andrés' \\ Luis Vazquez-Vazquez ${ }^{2}$ \\ Maria A Martinez-Huedo 3 \\ Valentín Hernández- \\ Barrera' \\ Isabel Jimenez-Trujillo' \\ Miguel A Tapias-Ledesma' \\ Javier de Miguel-Diez ${ }^{4,5}$ \\ Rodrigo Jiménez-García' \\ 'Preventive Medicine and Public \\ Health Teaching and Research Unit, \\ Health Sciences Faculty, Universidad \\ Rey Juan Carlos, Alcorcón, Spain; \\ ${ }^{2}$ Human Anatomy and Embryology \\ Teaching and Research Unit, Health \\ Sciences Faculty, Universidad \\ Rey Juan Carlos, Alcorcón, Spain; \\ ${ }^{3}$ Preventive Medicine, La Paz \\ University Hospital, Madrid, Spain; \\ ${ }^{4}$ Respiratory Department, Gregorio \\ Marañon General University Hospital, \\ Medical School, Complutense \\ University, Madrid, Spain; ${ }^{5}$ Instituto \\ de Investigación Sanitaria Gregorio \\ Marañón (IiSGM), Madrid, Spain
}

Background: Periodontal disease is more prevalent and more severe among men and women suffering from chronic obstructive pulmonary disease (COPD) compared with healthy adults. The objectives of this paper were to assess the association between periodontal disease and COPD, controlling the effect of sociodemographic characteristics, oral health status, lifestyle variables, and comorbidities. Second, we identified which of the variables analyzed were independently associated with periodontal disease among COPD sufferers.

Methods: This descriptive study was done with data from the National/European Health Interview Surveys, conducted in years 2006, 2011/12, and 2014 in Spain. We included subjects $\geq 40$ years of age. COPD status was self-reported. One non-COPD patient was matched by age, gender, and the year of survey for each COPD case. The presence of periodontal disease was defined using the answers "my teeth bleed spontaneously or while brushing" or/and "my teeth move" to the question: "Do you suffer of any of these dental and oral disorders or diseases?" Independent variables included demographic, socioeconomic, and health care-related variables, oral health status, and presence of comorbidities.

Results: The prevalence of periodontal disease was higher among COPD patients than their matched non-COPD controls $(26.5 \%$ vs $22.2 \%$; $P<0.001)$. Adjusted odds ratio (AOR) of periodontal disease for subjects with COPD was 1.21 (95\% CI: 1.12-1.30). Suffering mental disorders (AOR: 1.61; 95\% CI: 1.32-1.97) was positively associated with higher risk of periodontal disease. Older age, having a private dental health insurance, and university education were variables associated with lower rates of periodontal disease.

Conclusion: Prevalence of periodontal disease was higher among those with COPD compared to non-COPD controls. Dentists and physicians should increase their awareness with their COPD patients, especially those who are younger, with lower education, and suffer depression and/or anxiety.

Keywords: periodontal disease, COPD, survey, educational level

\section{Background}

Is well known that chronic obstructive pulmonary disease (COPD) is an important public health problem worldwide, causing high rates of disability mortality. ${ }^{1} \mathrm{COPD}$ commonly appears associated with other comorbidities that are thought to share an underlying inflammatory process, systemic or organ-specific, including a chronic inflammatory oral disease such as periodontal disease. ${ }^{2}$ Shi et $\mathrm{al}^{3}$ conducted a metaanalysis finding that COPD is related with several symptoms of periodontal disease including, lower number of remaining teeth, deeper periodontal pockets, more gingival bleeding and inflammation, and worse oral hygiene.

Periodontal disease is more severe and frequent among COPD patients compared with healthy adults. Shen et $\mathrm{al}^{4}$ observed a 1.19 -fold greater incidence of periodontal
Correspondence: Rodrigo Jiménez-García Preventive Medicine and Public Health Teaching and Research Unit, Health Sciences Faculty, Rey Juan Carlos University, Avda de Atenas s/n, 28922

Alcorcón, Madrid, Spain

$\mathrm{Tel}+34914888623$

Fax +34 91 4888848

Email rodrigo.jimenez@urjc.es 
diseases in COPD than non-COPD subjects, increasing to 3.17-fold greater among COPD patients that required hospitalization. Chung et $\mathrm{al}^{5}$ also demonstrated that among COPD male patients, moderate and severe periodontal disease were 1.38 (95\% CI: 1.12-2.05) and 1.23 (95\% CI: 1.06-1.56) times more prevalent, respectively, than among non-COPD males. However, no association was found among females. ${ }^{5}$

COPD and periodontal disease share risk factors such as tobacco use, higher age, and poverty. ${ }^{6}$ Prasanna ${ }^{7}$ concluded that periodontal disease by itself is not a cause for COPD, rather periodontal disease associated with other risk factors can accelerate the progression or the exacerbation of the disease. From a public health perspective, this is relevant, as it suggests that early oral intervention to prevent the evolution of periodontal disease could also have a beneficial effect on lung function.

The objectives of this paper are to assess the association between periodontal disease and COPD, controlling the effect of sociodemographic characteristics, oral health status, lifestyle variables, and comorbidities. Second, we identified which of these variables were independently associated with periodontal disease among COPD sufferers.

\section{Methods}

\section{Study design, setting, and participants}

We have done a descriptive study using data obtained from two Spanish National Health Surveys (NHS) corresponding to years 2006 and 2011/2012 and one European Health Interview Surveys for Spain (EHSS) for year 2014. These surveys are designed to obtain representative data of the Spanish population aged $\geq 15$ years and noninstitutionalized. Interviewers go the households and conduct face-to-face interviews. Collection periods were June 2006-June 2007 for the NHS 2006, July 2011-June 2012 for NHS 2011/2012, and January-December 2014 for the EHSS 2014. More detailed methods are describe elsewhere. ${ }^{8,9} \mathrm{We}$ selected participants aged $\geq 40$ years (NHS 2006, $n=20,060$; NHS 2011/2012, $\mathrm{n}=14,584$; EHSS 2014, $\mathrm{n}=16,498)$.

\section{Study variables and data sources/ measurement}

The variables used in our investigation were created using questions included in all surveys used and identically worded.

We considered participants suffering COPD as those who answered "yes" to any or both of the questions: "Has your doctor told you that you are currently suffering from chronic bronchitis or emphysema or COPD?" and/or "Have you taken any medication to treat bronchitis or emphysema or COPD in the last 2 weeks?"
Those participants who answered negatively to these questions were considered not COPD patients. For each participant suffering COPD (case), we found in the database of the same survey a matched participant not suffering the disease (control) who had the same age, gender, and lived in the same region. In case we found two or more controls per case, the selection of the control to be included was done randomly. The selection of controls was done one by one, individually, not using clustering methods.

Participants were considered as periodontal disease sufferers if when asked "Do you suffer of any of these dental and oral disorders or disease?" they answered "my teeth bleed spontaneously or while brushing" or/and "my teeth move."

The independent variables analyzed included the following:

1. Demographic and socioeconomic variables, including; age, gender, educational level (no studies/primary, secondary, high education), monthly income $(<900 €$, $900-2,000 €$, and $>2,000 €$ ), and living with a partner ("yes/no").

2. Lifestyle, including obesity (self-reported body mass index $\geq 30 \mathrm{~kg} / \mathrm{m}^{2}$ ), physical exercise ("yes/no" answer to the questions if the participant was engaged in any leisure time physical activity 2 or more days per week), tobacco use (nonsmoker, current smoker, and ex-smoker), and alcohol consumption ("yes" when the participant self-reported drinking any alcohol two times or more per month in the last 12 months).

3. Health status, including self-rated health (fair/poor/very poor vs very good/good), self-reported physician-diagnosed comorbid chronic conditions (osteoporosis, diabetes, cancer, and high blood pressure and/or heart disease), and mental disorders (anxiety and/or depression).

4. Oral health status, including self-reported caries, selfreported teeth extraction, self-reported dental filling, self-reported missing any teeth, and self-reported keeping all my natural teeth.

5. Use of health care services, including self-reported admission to hospital for at least one night in the previous year, self-reported visit to an emergency department for any medical condition in the previous year, and self-reported visit to a general physician in the last 4 weeks.

\section{Statistical analysis}

To describe categorical variables, we used proportions, and for continuous variables we used means with SD. We calculated and compared the prevalence of periodontal disease overall, and according to study variables, for participants with COPD and matched controls. To compare these prevalences, 
we used bivariate conditional logistic regression models. The independent effect of these study variables was analyzed constructing a conditional multivariable logistic regression model with COPD yes/no being the dependent variable.

We applied the Fisher's exact test as bivariate method to assess which study variables were associated with periodontal disease in participants with COPD. As a multivariable method, we again used unconditional logistic regression, now including "periodontal disease yes/no" as the dependent variable.

To build the logistic regression multivariable models (conditional and unconditional), we followed the recommendations of Hosmer et al. ${ }^{10}$ The process included the following steps:

1. For each study variable, bivariate analysis to assess its association with the dependent variable.

2. Selection of variables for the multivariable analysis. We included those variables with a significant association in the bivariate tests and other study variables, which even if not significant, were found important by other authors in the references reviewed. At this point, we decided to exclude from the multivariable analysis the variables "reasons for the last visit" as these variables showed a very high and significant concordance with the variables measuring "oral health status."

3. To decide which independent variables remain in the final model, we used the Wald statistic after including them one by one. Consecutive models created as new variables were included and compared with the previous ones using the Likelihood ratio test.

4. Once the final model was decided on, we checked for the possible presence of linearity and interactions between variables in the model. We limited interaction to firstorder $(2 \times 2)$ interactions. None of the linearity or interaction analyses showed a significant association.

The result of the regression models are shown as the odds ratio (OR) with 95\% confidence intervals.

STATA 14 program (StataCorp, College Station, TX, USA) was used for matching, statistical calculations, and multivariable model construction (enter modeling function). Significance limit was $\alpha<0.05$ (two-tailed).

\section{Ethical aspects}

The Spanish legislation rules that when public access databases with anonymous information are used for investigation, it is not necessary to obtain an ethics committee approval.

\section{Results}

In the 3 surveys, $2,721(5.32 \%)$ participants aged 40 years or over self-reported suffering COPD.
Previous to matching, COPD patients were significantly older than non-COPD participants (63 years SD 14 vs 61 years $\mathrm{SD} 14 ; P<0.001)$.

We found controls for 2,699 of the 2,721 participants with COPD, ie, $99.2 \%$.

The characteristics of the subject suffering from COPD and their non-COPD controls are shown in Table 1.

COPD participants have worse educational and economical level than matched non-COPD controls.

Body mass index $\geq 30$ was found in $37.3 \%$ of COPD and $26.8 \%$ of non-COPD participants $(P<0.001)$. Prevalence of the number of current smokers was higher in COPD subjects than in the non-COPD group ( $28.1 \%$ vs $17.6 \%, P<0.001)$.

Fair/poor/very poor self-reported health, diabetes, hypertension and/or heart disease, osteoporosis, cancer, and mental disorders were significantly more prevalent among the COPD participants.

Regarding oral health status, 28.4\% COPD subjects reported caries, $88.0 \%$ extraction of any teeth, $62.3 \%$ missing any teeth, and $6.7 \%$ keeping all teeth, with the figures for the non-COPD controls being $25.0 \%, 85.8 \%, 57.8 \%$, and $8.7 \%(P<0.05)$.

The prevalence of periodontal disease was $26.5 \%$ in those with COPD and $22.0 \%$ among matched non-COPD controls $(P<0.001)$.

Regarding variables of health care resources use, the visits to the general practitioner, hospitalization, and emergency room visit were higher in COPD subjects than in non-COPD subjects $(57.8 \%$ vs $45.7 \%, 18.4 \%$ vs $10.7 \%$ and $42.8 \%$ vs $27.6 \%$, respectively, all $P<0.001$ ).

Dental public health insurance was used by $12.7 \%$ of COPD sufferers and $9.6 \%$ of non-COPD sufferers $(P<0.001)$. Regarding oral treatment in their last visit to the dentist, 39.8\% COPD subjects reported dental check-up and $28.4 \%$ dental cleaning, with the equivalent frequencies for the non-COPD being significantly higher, $42.6 \%$ and $30.9 \%(P<0.05)$.

In Table 2 are shown the prevalence of periodontal disease participants with and without COPD according to demographic and socioeconomic and lifestyles variables.

Periodontal disease was significantly more prevalent among COPD sufferers than non-COPD sufferers in both genders, in those aged 55 years old or over, in those who had not studied, in those in the " $<900 €$ " monthly income category, in those living with a partner, and in those who were current smokers, ex-smokers, and never smoked.

In COPD subjects, the highest frequency of periodontal disease appeared in the 40-59 years old age group. Prevalence rose as the educational level decreased $(28.7 \%$ for 
Table I Distribution of the subject suffering from COPD and their age- and sex-matched non-COPD controls according to study variables

\begin{tabular}{|c|c|c|c|c|}
\hline Variable & Category & COPD, N (\%) & No COPD, N (\%) & $P$-value \\
\hline \multirow[t]{3}{*}{ Age groups } & $40-54$ years & $866(32.1)$ & $866(32.1)$ & \multirow[t]{3}{*}{ NA } \\
\hline & $55-64$ years & $557(20.6)$ & $557(20.6)$ & \\
\hline & 65 years or more & $\mathrm{I}, 276(47.3)$ & I,276 (47.3) & \\
\hline Gender & Female & I,767 (65.5) & I,767 (65.5) & NA \\
\hline \multirow[t]{3}{*}{ Educational level } & No studies/primary & $\mathrm{I}, 642(61.0)$ & I,548 (57.4) & \multirow[t]{3}{*}{0.030} \\
\hline & Secondary & $552(20.5)$ & $606(22.5)$ & \\
\hline & High education & $499(18.5)$ & $54 \mid(20.1)$ & \\
\hline \multirow[t]{3}{*}{ Monthly income } & $<900 €$ & $912(40.2)$ & 79I (35.5) & \multirow[t]{3}{*}{0.005} \\
\hline & $900-2,000 €$ & $966(42.5)$ & I,012 (45.4) & \\
\hline & $>2,000 €$ & $393(17.3)$ & $425(19.1)$ & \\
\hline Living with a partner & Yes & I,538 (57.0) & I,579 (58.5) & 0.270 \\
\hline Obesity & Yes & $885(37.3)$ & $630(26.8)$ & $<0.00$ I \\
\hline Physical exercise & Yes & $185(6.9)$ & $219(8.1)$ & 0.079 \\
\hline \multirow[t]{3}{*}{ Tobacco use } & Current smoker & $759(28.1)$ & $473(17.6)$ & \multirow[t]{3}{*}{$<0.001$} \\
\hline & Ex-smoker & I,536 (57.0) & $609(22.6)$ & \\
\hline & Never & $402(14.9)$ & $1,613(59.9)$ & \\
\hline Alcohol consumption & Yes & $1,010(50.8)$ & I,042 (5I.3) & 0.729 \\
\hline Self-rated health & Fair/poor/very poor & I,783 (66.I) & $1,253(46.4)$ & $<0.001$ \\
\hline Diabetes & Yes & $438(16.2)$ & $319(11.8)$ & $<0.001$ \\
\hline Hypertension and/or heart disease & Yes & I, $198(44.4)$ & I,017 (37.7) & $<0.001$ \\
\hline Osteoporosis & Yes & $420(15.6)$ & $277(10.3)$ & $<0.001$ \\
\hline Cancer & Yes & $188(7.0)$ & $138(5.1)$ & 0.001 \\
\hline Mental disorders & Yes & $877(32.5)$ & $527(19.5)$ & $<0.001$ \\
\hline Self-reported caries & Yes & $766(28.4)$ & $674(25.0)$ & 0.005 \\
\hline Self-rated extraction of teeth & Yes & $2,376(88.0)$ & $2,316(85.8)$ & 0.015 \\
\hline Self-reported dental filling & Yes & $\mathrm{I}, 498(55.5)$ & I,522 (56.4) & 0.528 \\
\hline Self-reported missing any teeth & Yes & $\mathrm{I}, 682(62.3)$ & $1,559(57.8)$ & 0.001 \\
\hline Self-reported keeping all natural teeth & Yes & $182(6.7)$ & $236(8.7)$ & 0.006 \\
\hline General practitioner visit in the last 4 weeks & Yes & $\mathrm{I}, 56 \mathrm{I}(57.8)$ & $1,234(45.7)$ & $<0.001$ \\
\hline Hospital admission in the last 12 months & Yes & $496(18.4)$ & $289(10.7)$ & $<0.001$ \\
\hline Emergency room visit in the last 12 months & Yes & $\mathrm{I}, 155(42.8)$ & $744(27.6)$ & $<0.001$ \\
\hline Last visit to the dentist in the last 3 months & Yes & $467(17.3)$ & $425(15.7)$ & 0.456 \\
\hline \multirow[t]{3}{*}{ Dental insurance type } & Public health insurance & $333(12.7)$ & $252(9.6)$ & \multirow[t]{3}{*}{0.001} \\
\hline & Private insurance & $948(36.1)$ & $962(36.5)$ & \\
\hline & Fully private practice & $1,345(51.2)$ & $\mathrm{I}, 419(53.9)$ & \\
\hline Reason for last visit "check-up" & Yes & $\mathrm{I}, 05 \mathrm{I}(39.8)$ & $\mathrm{I}, \mathrm{I} 26(42.6)$ & $0.04 I$ \\
\hline Reason for last visit "dental cleaning" & Yes & $750(28.4)$ & $818(30.9)$ & 0.047 \\
\hline Reason for last visit "filling" & Yes & $532(20.1)$ & $536(20.3)$ & 0.918 \\
\hline Reason for last visit "extractions" & Yes & $676(25.6)$ & $621(23.5)$ & 0.079 \\
\hline Reason for last visit "prosthesis treatment" & Yes & $717(27.1)$ & $694(26.2)$ & 0.456 \\
\hline Periodontal disease & Yes & $715(26.5)$ & $600(22.2)$ & $<0.001$ \\
\hline
\end{tabular}

Abbreviation: COPD, chronic obstructive pulmonary disease.

no studies/primary category vs $20.2 \%$ for high education category). Subjects with obesity and who did not practice any leisure time physical activity for more than 2 days a week showed a higher prevalence of periodontal disease
( $28.7 \%$ and $27.1 \%$ vs $24.6 \%$ and $18.4 \%$, respectively, all $P<0.05)$.

In non-COPD subjects, prevalence of periodontal disease increased as educational level and monthly income 
Table 2 Prevalence of periodontal disease among COPD subjects and age- and sex-matched non-COPD controls according to demographic and socioeconomic variables and lifestyles

\begin{tabular}{|c|c|c|c|c|}
\hline Variable & Category & COPD, N (\%) & No COPD, N (\%) & $P$-value \\
\hline \multirow[t]{3}{*}{ Age groups } & $40-54$ years & $246(28.4)$ & $210(24.2)$ & 0.050 \\
\hline & $55-64$ years & $166(29.8)$ & $|3|(23.5)$ & 0.018 \\
\hline & 65 years or more & $303(23.7)$ & $259(20.3)$ & 0.036 \\
\hline \multirow[t]{2}{*}{ Gender } & Male & $246(26.4)$ & 195 (20.9) & 0.004 \\
\hline & Female & $469(26.5)$ & $405(22.9)$ & $<0.001$ \\
\hline \multirow[t]{3}{*}{ Educational level } & No studies/primary & 47I (28.7) & $371(24.0)$ & 0.002 \\
\hline & Secondary & $143(25.9)$ & $123(20.3)$ & 0.258 \\
\hline & High education & I0I (20.2) & $106(19.6)$ & 0.210 \\
\hline \multirow[t]{3}{*}{ Monthly income ${ }^{b}$} & $<900 €$ & $262(28.7)$ & $212(26.8)$ & 0.042 \\
\hline & $900-2,000 €$ & $255(26.4)$ & $216(21.39)$ & 0.133 \\
\hline & $>2,000 €$ & $96(24.4)$ & $85(20.0)$ & 0.068 \\
\hline \multirow[t]{2}{*}{ Living with a partner } & No & $302(26.1)$ & $246(22.0)$ & 0.076 \\
\hline & Yes & $412(26.8)$ & $354(22.4)$ & 0.001 \\
\hline \multirow[t]{2}{*}{ Obesity ${ }^{\mathrm{a}, \mathrm{b}}$} & No & $366(24.6)$ & $358(20.8)$ & $<0.001$ \\
\hline & Yes & $254(28.7)$ & $162(25.7)$ & 0.663 \\
\hline \multirow[t]{2}{*}{ Physical exercise $^{a}$} & No & $681(27.1)$ & $56 \mid(22.6)$ & $<0.001$ \\
\hline & Yes & $34(18.4)$ & $39(17.8)$ & 0.9 \\
\hline \multirow[t]{3}{*}{ Tobacco use } & Current smoker & $205(27.0)$ & $99(20.9)$ & 0.003 \\
\hline & Ex-smoker & $398(25.9)$ & $134(22.0)$ & 0.006 \\
\hline & Never & $112(27.9)$ & $366(22.7)$ & 0.01 \\
\hline \multirow[t]{2}{*}{ Alcohol consumption } & No & $275(28.1)$ & $199(20.1)$ & 0.005 \\
\hline & Yes & $262(25.9)$ & $252(24.2)$ & 0.145 \\
\hline
\end{tabular}

Notes: $P$-value: significant differences $(P<0.05)$ between COPD sufferers and non-COPD sufferers for periodontal disease. Comparisons conducted using conditional

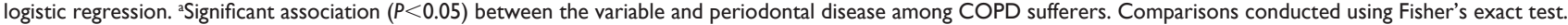
'Significant association $(P<0.05)$ between the variable and periodontal disease among non-COPD sufferers. Comparisons conducted using Fisher's exact test. Abbreviation: COPD, chronic obstructive pulmonary disease.

decreased. Subjects with obesity and alcohol consumers showed a higher prevalence of periodontal disease.

Table 3 shows the findings when we compared the prevalence of periodontal disease according to comorbidities and oral health status variables.

Regarding self-reported health, besides COPD status, those with "Fair/poor/very poor" had significantly higher prevalence of periodontal disease than those with "Very good/good" self-rated health. Suffering mental disorders, caries, extraction of teeth, dental filling, and missing teeth were associated with a higher prevalence of periodontal disease compared to those without these diseases in both groups of patients. In COPD subjects, prevalence of periodontal disease was higher in those with diabetes and osteoporosis (31.5\% and $31.4 \%$ vs $25.5 \%$ and $25.6 \%$, respectively, all $P<0.05)$.

Periodontal disease was significantly more frequent among COPD sufferers than among people without COPD in subjects with fair/poor/very poor self-rated health, in those with hypertension and/or heart disease, in those with extraction of teeth, in those with dental filling, and in those with missing teeth. However, periodontal disease was significantly more prevalent among COPD subjects who did not suffer from osteoporosis, cancer, or mental disorders, as can been seen in Table 3 .

The prevalence of periodontal disease among COPD subjects and non-COPD controls according to health care resources use is shown in Table 4.

When we compared the prevalence of periodontal disease between COPD subjects and controls for use of health resources variables, a significantly higher prevalence was found for general practitioner visit in the last 4 weeks $(28.3 \%$ vs $23.6 \%$ ), no hospitalization ( $25.7 \%$ vs $22.1 \%$ ), and for no emergency room visit in the last year $(25.2 \%$ vs $21.6 \%)$.

Besides COPD status, the highest prevalence was found in those who used dental public health insurance, had extractions of teeth, and did not undergo prosthesis treatments. In COPD subjects, prevalence of periodontal disease was higher in those who had an emergency room visit in the last year $(29.9 \%$ vs $24.0 \%, P<0.05)$, as can be seen in Table 4 . 
Table 3 Prevalence of periodontal disease among COPD subjects and age- and sex-matched non-COPD controls according to comorbidities and oral health variables

\begin{tabular}{|c|c|c|c|c|}
\hline Variable & Category & COPD, N (\%) & No COPD, N (\%) & $P$-value \\
\hline \multirow[t]{2}{*}{ Self-rated health ${ }^{\mathrm{a}, \mathrm{b}}$} & Very good/good & $185(20.2)$ & $276(19.1)$ & 0.090 \\
\hline & Fair/poor/very poor & $530(29.7)$ & $324(25.9)$ & 0.027 \\
\hline \multirow[t]{2}{*}{ Diabetes $^{\mathrm{a}}$} & No & $577(25.5)$ & $526(22.1)$ & 0.001 \\
\hline & Yes & $138(3 \mid .5)$ & $74(23.2)$ & 0.134 \\
\hline \multirow[t]{2}{*}{ Hypertension and/or heart disease } & No & $378(25.2)$ & $365(21.7)$ & 0.039 \\
\hline & Yes & $337(28.1)$ & $235(23.1)$ & $<0.001$ \\
\hline \multirow[t]{2}{*}{ Osteoporosis ${ }^{\mathrm{a}}$} & No & $583(25.6)$ & $528(21.8)$ & $<0.001$ \\
\hline & Yes & $132(3 \mid .4)$ & $72(26.0)$ & 0.244 \\
\hline \multirow[t]{2}{*}{ Cancer } & No & $663(26.4)$ & $56 \mid(2 I .9)$ & $<0.001$ \\
\hline & Yes & $52(27.7)$ & $39(28.3)$ & $0.57 \mathrm{I}$ \\
\hline \multirow[t]{2}{*}{ Mental disorders ${ }^{\mathrm{a}, \mathrm{b}}$} & No & $422(23.2)$ & $428(19.7)$ & 0.001 \\
\hline & Yes & $293(33.4)$ & $172(32.6)$ & 0.072 \\
\hline \multirow[t]{2}{*}{ Self-reported caries ${ }^{\mathrm{a}, \mathrm{b}}$} & No & $364(18.8)$ & $342(16.9)$ & 0.007 \\
\hline & Yes & $35 \mathrm{I}(45.8)$ & $258(38.3)$ & 0.362 \\
\hline \multirow[t]{2}{*}{ Self-reported extraction of teeth $\mathrm{h}^{\mathrm{a}, \mathrm{b}}$} & No & $58(18.0)$ & $44(\mathrm{II} .5)$ & 0.808 \\
\hline & Yes & $657(27.7)$ & $556(24.0)$ & $<0.001$ \\
\hline \multirow[t]{2}{*}{ Self-reported dental filling ${ }^{\mathrm{a}, \mathrm{b}}$} & No & $281(23.4)$ & $232(19.7)$ & 0.115 \\
\hline & Yes & $434(29.0)$ & $368(24.2)$ & 0.002 \\
\hline \multirow[t]{2}{*}{ Self-reported missing teeth ${ }^{\mathrm{a}, \mathrm{b}}$} & No & $184(18.1)$ & $162(14.2)$ & 0.076 \\
\hline & Yes & $53 I(3 I .6)$ & $438(28.1)$ & 0.017 \\
\hline \multirow[t]{2}{*}{ Self-reported keeping all natural teeth ${ }^{\mathrm{a}, \mathrm{b}}$} & No & $686(27.3)$ & $568(23.1)$ & $<0.001$ \\
\hline & Yes & $29(15.9)$ & $32(13.6)$ & 0.530 \\
\hline
\end{tabular}

Notes: $P$-value: significant differences $(P<0.05)$ between COPD sufferers and non-COPD sufferers for periodontal disease. Comparisons conducted using conditional logistic regression. aSignificant association $(P<0.05)$ between the variable and periodontal disease among COPD sufferers. Comparisons conducted using Fisher's exact test. 'Significant association $(P<0.05)$ between the variable and periodontal disease among non-COPD sufferers. Comparisons conducted using Fisher's exact test. Abbreviation: COPD, chronic obstructive pulmonary disease.

The result of the multivariable models to assess the association of COPD with periodontal disease showed that, after controlling for possible confounders, suffering from COPD increased the probability of reporting periodontal disease by 21\% (OR: 1.21; 95\% CI: 1.12-1.30) (Table 5). As can be seen in Table 5, COPD was also associated with reporting more obesity and being a current or ex-smoker. Regarding health status, COPD cases had significant higher probability of reporting worse self-rated health, diabetes, hypertension and/or heart disease, osteoporosis, and mental disorders than matched non-COPD controls. Furthermore, COPD sufferers had used all the health care services analyzed significantly more than non-COPD controls.

The factors associated with suffering periodontal disease among COPD sufferers are shown in Table 6.

Older age was found to be associated with a lower probability of reporting periodontal disease compared to younger COPD subjects. Having lower educational level and selfreported mental disorders raised the probability of suffering from periodontal disease.
Among COPD subjects, those with private dental insurance had lower prevalence of periodontal disease than those who had public health insurance (OR: $0.50 ; 95 \%$ CI: $0.37-0.67$ ), and those who visited to the dentist 12 months or over had lower prevalence of periodontal disease than those who visited the dentist within the last 3 months (OR: 0.77; 95\% CI: $0.60-0.98)$.

\section{Discussion}

Our main finding was that suffering COPD is associated with a higher prevalence of periodontal disease after multivariable adjustment, including several sociodemographic characteristics and health-related variables. Also, among factors that we studied in COPD subjects, younger age, lower educational level, and self-reported mental disorders were significantly related with periodontal disease prevalence. However, visiting a fully private dentist and having visited the dentist less frequently were associated with lower risk of periodontal disease.

Several previous studies have been conducted to assess the relationship between COPD and clinical markers of 
Table 4 Prevalence of periodontal disease among COPD subjects and age- and sex-matched non-COPD controls according to health care resources use and oral health care resources use

\begin{tabular}{|c|c|c|c|c|}
\hline Variable & Category & COPD, N (\%) & No COPD, N (\%) & $P$-value \\
\hline \multirow[t]{3}{*}{ General practitioner visit } & $<4$ weeks & $442(28.3)$ & $291(23.6)$ & 0.003 \\
\hline & 4 weeks- 12 months & $231(23.69)$ & $245(21.7)$ & 0.669 \\
\hline & $>12$ months & $42(26.6)$ & $64(19.5)$ & 0.118 \\
\hline \multirow[t]{2}{*}{ Hospital visit in the last 12 months } & No & $567(25.7)$ & $533(22.1)$ & $<0.001$ \\
\hline & Yes & $148(29.8)$ & $67(23.2)$ & 0.655 \\
\hline \multirow[t]{2}{*}{ Emergency room visit in the last 12 months $^{a}$} & No & $370(24.0)$ & $426(21.8)$ & 0.001 \\
\hline & Yes & $345(29.9)$ & $174(23.4)$ & 0.385 \\
\hline \multirow[t]{4}{*}{ Last visit to the dentist } & $<3$ months & $142(30.4)$ & $88(20.7)$ & 0.001 \\
\hline & $3-12$ months & $146(26.4)$ & $143(25.3)$ & 0.651 \\
\hline & 12 months or over & $408(25.2)$ & $358(21.6)$ & 0.018 \\
\hline & Never & $19(32.8)$ & II (20.4) & 0.142 \\
\hline \multirow[t]{3}{*}{ Dental insurance type $e^{a, b}$} & Public health insurance & $140(42.0)$ & $87(34.5)$ & 0.147 \\
\hline & Private insurance & $244(25.7)$ & $220(22.9)$ & 0.004 \\
\hline & Fully private practice & $308(22.9)$ & $280(19.7)$ & 0.063 \\
\hline \multirow[t]{2}{*}{ Reason for last visit "check-up” } & No & $4 I I(25.8)$ & $342(22.5)$ & 0.039 \\
\hline & Yes & $285(27.1)$ & $247(21.9)$ & $<0.001$ \\
\hline \multirow[t]{2}{*}{ Reason for last visit "dental cleaning" } & No & $504(26.7)$ & $387(21.2)$ & 0.222 \\
\hline & Yes & $192(25.6)$ & $202(24.7)$ & $<0.001$ \\
\hline \multirow[t]{2}{*}{ Reason for last visit "filling" } & No & $556(26.4)$ & $470(22.3)$ & $<0.001$ \\
\hline & Yes & $140(26.3)$ & $119(22.2)$ & 0.457 \\
\hline \multirow[t]{2}{*}{ Reason for last visit "extractions"a,b } & No & $474(24.1)$ & $416(20.6)$ & $<0.001$ \\
\hline & Yes & $222(32.8)$ & $173(27.9)$ & 0.227 \\
\hline \multirow[t]{2}{*}{ Reason for last visit "prosthesis treatment" } & No & $55 \mathrm{I}(28.6)$ & $462(23.7)$ & $<0.001$ \\
\hline & Yes & I45 (20.2) & I27 (I8.3) & 0.379 \\
\hline
\end{tabular}

Notes: $P$-value: significant differences $(P<0.05)$ between COPD sufferers and non-COPD sufferers for periodontal disease. Comparisons conducted using conditional logistic regression. ${ }^{a}$ Significant association $(P<0.05)$ between the variable and periodontal disease among COPD sufferers. Comparisons conducted using Fisher's exact test. bSignificant association $(P<0.05)$ between the variable and periodontal disease among non-COPD sufferers. Comparisons conducted using Fisher's exact test.

Abbreviation: COPD, chronic obstructive pulmonary disease.

periodontal disease and tooth loss. ${ }^{1,11-14} \mathrm{We}$ found that suffering COPD increased the probability of reporting periodontal disease by $21 \%$, which means that patients with COPD suffer from periodontal diseases more frequently than the general population.

Other authors agree with our finding and have shown that periodontal disease is a significant and independent risk factor of COPD. ${ }^{3,5,7,15,16}$ Shen et al ${ }^{17}$ conducted a propensity-matched retrospective cohort study and found that periodontal treatment is effective to reduce the number of respiratory events among COPD patients and concluded the relevance of periodontal health in these patients. A clinical trial confirmed that periodontal treatment reduces exacerbation frequency and improves lung function in COPD sufferers. ${ }^{18}$

Advanced age has been associated with periodontal disease in the general population and among COPD sufferers. ${ }^{19}$ Our results showed a decreasing trend of periodontal disease prevalence with age (65 years or over). This result is coherent with a systematic review, including studies from several countries, finding that the highest incidence of severe periodontitis was at 38 years even if the overall incidence rose steadily from 30 to 80 years. However, the results showed important differences between countries and regions. ${ }^{20}$ Among younger people, periodontal problems appear as mild periodontitis, consequence of a bad oral hygiene, and gingivitis. ${ }^{21}$ Furthermore, Hassel et $\mathrm{a}^{22}$ followed two birth cohorts for 10 years, conducting periodic clinical explorations, finding that older people had lost progressively more teeth, reflecting loss rates of 5\% in the young cohort (born in $1950 / 1952$ ) and $14 \%$ in the older cohort (born in 1930/1932). It seems that, while patients have any remaining teeth they are aware of their periodontal disease but, when they lose all of their teeth, they become unconscious of this problem. As our study is based on self-reported data, prevalence of periodontal disease is possibly underestimated for older people. 
Table 5 Result of the multivariable conditional logistic regression model using COPD/non-COPD as the dependent variable and adjusted by the study variables

\begin{tabular}{|c|c|c|}
\hline Variable & Category & OR $(95 \% \mathrm{Cl})$ \\
\hline \multirow[t]{2}{*}{ Obesity } & No & 1 \\
\hline & Yes & $1.32(1.22-1.48)$ \\
\hline \multirow[t]{3}{*}{ Tobacco use } & Never & 1 \\
\hline & Ex-smoker & $2.48(2.3 \mathrm{I}-2.69)$ \\
\hline & Current smoker & $1.75(1.62-1.96)$ \\
\hline \multirow[t]{2}{*}{ Self-rated health } & Very good/good & 1 \\
\hline & Fair/poor/very poor & $1.48(1.34-1.65)$ \\
\hline \multirow[t]{2}{*}{ Diabetes } & No & \\
\hline & Yes & $1.31(1.19-1.47)$ \\
\hline \multirow[t]{2}{*}{ Hypertension and/or heart disease } & No & 1 \\
\hline & Yes & $1.21(1.11-1.34)$ \\
\hline \multirow[t]{2}{*}{ Osteoporosis } & No & 1 \\
\hline & Yes & $1.42(1.26-1.61)$ \\
\hline \multirow[t]{2}{*}{ Mental disorders } & No & 1 \\
\hline & Yes & $1.84(1.67-2.11)$ \\
\hline \multirow[t]{2}{*}{ General practitioner visit in the last 4 weeks } & No & 1 \\
\hline & Yes & $1.38(1.26-1.55)$ \\
\hline \multirow[t]{2}{*}{ Hospital admission in the last 12 months } & No & 1 \\
\hline & Yes & $1.86(1.70-2.09)$ \\
\hline \multirow[t]{2}{*}{ Emergency room visit in the last 12 months } & No & 1 \\
\hline & Yes & $1.68(1.52-1.84)$ \\
\hline \multirow[t]{2}{*}{ Periodontal disease } & No & 1 \\
\hline & Yes & $1.21(1.12-1.30)$ \\
\hline
\end{tabular}

Notes: Independent variables included in the model were all those with a significant difference between COPD cases and non-COPD controls (shown in Table I) except "reasons for the last visit to the dentist." In the current table, only those variables with a significant OR are shown.

Abbreviations: COPD, chronic obstructive pulmonary disease; OR, odds ratio.

Table 6 Factors associated with periodontal disease among COPD sufferers

\begin{tabular}{|l|l|l|}
\hline Variable & Category & OR (95\% Cl) \\
\hline \multirow{4}{*}{ Age } & $40-54$ years & $\mathrm{I}$ \\
\cline { 2 - 3 } & $55-64$ years & $0.83(0.63-1.08)$ \\
\cline { 2 - 3 } & 65 years or more & $0.5 \mathrm{I}(0.39-0.66)$ \\
\hline \multirow{5}{*}{ Educational level } & No studies/primary & $\mathrm{I}$ \\
\cline { 2 - 3 } & Secondary & $0.77(0.59-\mathrm{I} .0 \mathrm{I})$ \\
\cline { 2 - 3 } & High education & $0.57(0.42-0.76)$ \\
\hline \multirow{5}{*}{ Dental insurance type } & $<3$ months & $\mathrm{I}$ \\
\cline { 2 - 3 } & $3-12$ months & $0.92(0.68-1.23)$ \\
\cline { 2 - 3 } & 12 months or over & $0.77(0.60-0.98)$ \\
\hline Mental disorders & Public health insurance & $\mathrm{I}$ \\
\cline { 2 - 3 } & Private insurance & $0.50(0.37-0.67)$ \\
\cline { 2 - 3 } & Fully private practice & $0.44(0.33-0.58)$ \\
\hline
\end{tabular}

Notes: OR estimated using multivariable unconditional logistic regression. Independent variables included in the model were all those with a significant difference in the prevalence of periodontal disease among COPD subjects and age- and sex-matched non-COPD controls (shown in Tables 2, 3, and 5) except "reasons for the last visit to the dentist." In the current table, only those variables with a significant OR are shown.

Abbreviations: COPD, chronic obstructive pulmonary disease; OR, odds ratio. 
As we expected, subjects with higher educational level are less likely to have periodontal disease, which is in line with that reported by other studies. ${ }^{5,7,19}$ Kim et al ${ }^{23}$ found that COPD patients, irrespective of whether they suffered from periodontal disease or not, had higher age, lower educational level, were more sedentary, reported less income, and consumed more tobacco and alcohol.

In our study, use of fully private oral health care services was associated with lower risk of periodontal disease among COPD subjects. The Spanish National Health System includes only dental extractions and emergency care as charge-free services in publicly funded clinics for adults. Most people in Spain are attended to by private dentist that provide them with all the oral health care services, including for periodontal disease. ${ }^{24}$

It has been found that regular visits to the dentist is a predictor of better oral health. ${ }^{25}$ One reason for the low use of dental services among COPD patients may be the high costs of care and treatment. ${ }^{26,27}$ Also, some authors found a relationship between missing teeth and the presence of COPD, indicating an increase in the number of edentulous subjects who do not seek care..$^{23,28-30}$

Being depressed has also been related to higher risk of periodontal disease, as it can lead to poorer self-care behaviors. ${ }^{31,32}$ In our study, COPD patients with self-reported mental disorders had a 1.61-fold higher probability of periodontal disease than those without mental disorders. This is mostly caused by the side effects of the medications that they receive, lack of self-care, difficulty in accessing health services, a negative attitude toward health care providers, and patients' lack of cooperation in dental treatments. ${ }^{33}$

Periodontal disease and COPD are strongly associated with tobacco smoking. ${ }^{19}$ In our study, despite the fact that the prevalence of periodontal disease was higher among COPD smokers than non-COPD smokers, we found no significant association with periodontal disease. We have found controversial results from several studies about this matter, as some of them reported a higher risk associated with smoking, with another one not finding a significant impact in the association of COPD and smoking habit on periodontal disease. ${ }^{27,34,35}$ Studies on nonsmoker COPD patients have also found an association of periodontal disease with COPD. ${ }^{12,36}$

We think that as smoke cessation is a recommend intervention for either periodontal disease or COPD, this may explain the lack of association in a descriptive investigation. Follow-up studies should clarify this point.
The strength of this study is the big sample size representative of an entire country, obtained using data from three consecutive surveys. By matching COPD participants with persons without COPD with identical age and gender, we can control the confounding effect of these two variables. Finally, the surveys collect many variables that cannot be found in the clinical setting.

Several limitations of our investigation should be mentioned. First, our results are based on self-reported oral health data, which could underestimate prevalence of the disease. Self-reported measures have been suggested recently as a reliable method for surveillance of periodontal disease or estimating burden and risk factors of the disease, due to the high cost and resources needed to obtain clinical data from professional oral examination. ${ }^{37,38}$ Second, we were unable to assess severity of periodontal disease, which can underestimate its prevalence. For example, periodontal disease may be unknown by the person, with no presenting symptoms. Prevalence of periodontal disease has been variably reported even with oral examined studies, depending on the protocol applied to measure the disease ${ }^{39}$ Nevertheless, estimated prevalence of periodontal disease was not the main objective of this study. Third, participants may forget or provide wrong information in the interviews (recall bias). Furthermore, it is possible that the answer given is what the participant considers the socially adequate response, not the real one. Fourth, differences in the questions included in the surveys used made it impossible to analyze in more detail smoking information.

\section{Conclusion}

We observed that prevalence of periodontal disease was significantly higher among those with COPD compared to their age- and sex-matched non-COPD controls, after controlling for possible confounders. Among COPD subjects, older age, high educational level, less frequent visit to the dentist, and use of private dental insurance were associated with lower likelihood of periodontal disease. Concomitant mental disorder was associated with suffering periodontal disease. Dentists, especially periodontists, and physicians should increase their awareness with their COPD patients, especially in those who are younger, and have mental disorders, as these have been found to be potential risk factors for periodontal disease.

\section{Acknowledgment}

This study is part of research funded by the FIS (Fondo de Investigaciones Sanitarias-Health Research Fund, grant no PI16/00564, Instituto de Salud Carlos III) cofinanced by the 
European Union through the Fondo Europeo de Desarrollo Regional (FEDER, “Una manera de hacer Europa”).

\section{Disclosure}

The authors report no conflicts of interest in this work.

\section{References}

1. Soriano JB, Rodríguez-Roisin R. Chronic obstructive pulmonary disease overview: epidemiology, risk factors, and clinical presentation. Proc Am Thorac Soc. 2011;8(4):363-367.

2. Global Initiative for Chronic Obstructive Lung Disease (GOLD). Global Strategy for the Diagnosis, Management, and Prevention of Chronic Obstructive Pulmonary Disease; 2017. Available from: https:// goldcopd.org/gold-2017-global-strategy-diagnosis-managementprevention-copd/. Accessed February 23, 2018.

3. Shi Q, Zhang B, Xing H, Yang S, Xu J, Liu H. Patients with chronic obstructive pulmonary disease suffer from worse periodontal healthevidence from a meta-analysis. Front Physiol. 2018;9:33.

4. Shen TC, Chang PY, Lin CL, et al. Risk of periodontal diseases in patients with chronic obstructive pulmonary disease: a nationwide population-based cohort study. Medicine. 2015;94(46):e2047.

5. Chung JH, Hwang HJ, Kim SH, Kim TH. Associations Between periodontitis and chronic obstructive pulmonary disease: the 2010 to 2012 Korean National Health and Nutrition Examination Survey. J Periodontol. 2016;87(8):864-871.

6. Hobbins S, Chapple IL, Sapey E, Stockley RA. Is periodontitis a comorbidity of COPD or can associations be explained by shared risk factors/ behaviors? Int J Chron Obstruct Pulmon Dis. 2017;12:1339-1349.

7. Prasanna SJ. Causal relationship between periodontitis and chronic obstructive pulmonary disease. J Indian Soc Periodontol. 2011;15(4): 359-365.

8. Instituto Nacional de Estadística. Encuesta Nacional de Salud. Madrid: Instituto Nacional de Estadística. Available from: http:/www.ine.es/ dyngs/INEbase/es/operacion.htm?c=Estadistica_C\&cid=12547361767 $83 \&$ menu=metodologia\&idp $=1254735573175$. Accessed February 23, 2018.

9. Instituto Nacional de Estadística. European Health Interview Survey. Madrid: Instituto Nacional de Estadística. Available from: http:// www.ine.es/dyngs/INEbase/es/operacion.htm?c=Estadistica_C\&cid= $1254736176784 \&$ menu $=$ resultados $\& i d p=1254735573175$. Accessed February 23, 2017.

10. Hosmer DW, Lemeshow S, Sturdivant RX. Applied Logistic Regression. 3rd ed. New Jersey: John Wiley \& Sons, Inc; 2013.

11. Peter KP, Mute BR, Doiphode SS, Bardapurkar SJ, Borkar MS, Raje DV. Association between periodontal disease and chronic obstructive pulmonary disease: a reality or just a dogma? J Periodontol. 2013;84(12): 1717-1723.

12. Vadiraj S, Nayak R, Choudhary GK, Kudyar N, Spoorthi BR. Periodontal pathogens and respiratory diseases-evaluating their potential association: a clinical and microbiological study. J Contemp Dent Pract. 2013;14(4):610-615.

13. Barros SP, Suruki R, Loewy ZG, Beck JD, Offenbacher S. A cohort study of the impact of tooth loss and periodontal disease on respiratory events among COPD subjects: modulatory role of systemic biomarkers of inflammation. PLoS One. 2013;8(8):e68592.

14. Offenbacher S, Barros SP, Altarawneh S, Beck JD, Loewy ZG. Impact of tooth loss on oral and systemic health. Gen Dent. 2012;60(6): 494-500.

15. Zeng XT, Tu ML, Liu DY, Zheng D, Zhang J, Leng W. Periodontal disease and risk of chronic obstructive pulmonary disease: a metaanalysis of observational studies. PLoS One. 2012;7(10):e46508.

16. Usher AK, Stockley RA. The link between chronic periodontitis and COPD: a common role for the neutrophil? BMC Med. 2013;11:241.
17. Shen TC, Chang PY, Lin CL, et al. Periodontal treatment reduces risk of adverse respiratory events in patients with chronic obstructive pulmonary disease: a propensity-matched cohort study. Medicine. 2016;95(20):e3735.

18. Zhou X, Han J, Liu Z, Song Y, Wang Z, Sun Z. Effects of periodontal treatment on lung function and exacerbation frequency in patients with chronic obstructive pulmonary disease and chronic periodontitis: a 2-year pilot randomized controlled trial. J Clin Periodontol. 2014; 41(6):564-572.

19. Almerich-Silla JM, Almiñana-Pastor PJ, Boronat-Catalá M, BellotArcís C, Montiel-Company JM. Socioeconomic factors and severity of periodontal disease in adults (35-44 years). A cross sectional study. J Clin Exp Dent. 2017;9(8):e988-e994.

20. Kassebaum NJ, Bernabé E, Dahiya M, Bhandari B, Murray CJ, Marcenes W. Global burden of severe periodontitis in 1990-2010: a systematic review and meta-regression. J Dent Res. 2014;93(11):1045-1053.

21. Kassebaum NJ, Smith AGC, Bernabé E, et al. Global, regional, and national prevalence, Incidence, and disability-adjusted life years for oral conditions for 195 countries, 1990-2015: a systematic analysis for the global burden of diseases, injuries, and risk factors. J Dent Res. 2017;96(4):380-387.

22. Hassel AJ, Safaltin V, Grill S, et al. Risk factors for tooth loss in middle and older age after up to 10 years: an observational cohort study. Arch Oral Biol. 2018;86:7-12.

23. Kim SW, Han K, Kim SY, Park CK, Rhee CK, Yoon HK. The relationship between the number of natural teeth and airflow obstruction: a cross-sectional study using data from the Korean National Health and Nutrition Examination Survey. Int J Chron Obstruct Pulmon Dis. 2016;11:13-21.

24. Bravo M, San Martín L, Casals E, Eaton KA, Widström E. The healthcare system and the provision of oral healthcare in European Union member states. Part 2: Spain. Br Dent J. 2015;219(11):547-551.

25. Thomson WM, Williams SM, Broadbent JM, Poulton R, Locker D. Long-term dental visiting patterns and adult oral health. $J$ Dent Res. 2010;89(3):307-311.

26. Palència L, Espelt A, Cornejo-Ovalle M, Borrell C. Socioeconomic inequalities in the use of dental care services in Europe: what is the role of public coverage? Community Dent Oral Epidemiol. 2014;42(2): 97-105.

27. Essue B, Kelly P, Roberts M, Leeder S, Jan S. We can't afford my chronic illness! The out-of-pocket burden associated with managing chronic obstructive pulmonary disease in western Sydney, Australia. $J$ Health Serv Res Policy. 2011;16(4):226-231.

28. Leuckfeld I, Obregon-Whittle MV, Lund MB, Geiran O, Bjørtuft Ø, Olsen I. Severe chronic obstructive pulmonary disease: association with marginal bone loss in periodontitis. Respir Med. 2008;102(4): 488-494.

29. Wang Z, Zhou X, Zhang J, et al. Periodontal health, oral health behaviours, and chronic obstructive pulmonary disease. J Clin Periodontol. 2009;36(9):750-755.

30. Suominen-Taipale AL, Widstrom E, Alanen P, Uutela A. Trends in self-reported use of dental services among Finnish adults during two decades. Community Dent Health. 2000;17(1):31-37.

31. Hsu CC, Hsu YC, Chen HJ, et al. Association of periodontitis and subsequent depression: a nationwide population-based study. Medicine. 2015;94(51):e2347.

32. Rosania AE, Low KG, Mccormick CM, Rosania DA. Stress, depression, cortisol, and periodontal disease. J Periodontol. 2009;80(2): 260-266.

33. Torales J, Barrios I, González I. Oral and dental health issues in people with mental disorders. Medwave. 2017;17(8):e7045.

34. Terashima T, Chubachi S, Matsuzaki T, et al. The association between dental health and nutritional status in chronic obstructive pulmonary disease. Chron Respir Dis. 2017;14(4):334-341.

35. Bergström J, Cederlund K, Dahlén B, et al. Dental health in smokers with and without COPD. PLoS One. 2013;8(3):e59492. 
36. Katancik JA, Kritchevsky S, Weyant RJ, et al. Periodontitis and airway obstruction. J Periodontol. 2005;76(11-s):2161-2167.

37. Eke PI, Wei L, Borgnakke WS, et al. Periodontitis prevalence in adults $\geq 65$ years of age, in the USA. Periodontol 2000. 2016;72(1):76-95.
38. Eke PI, Dye BA, Wei L, et al. Self-reported measures for surveillance of periodontitis. J Dent Res. 2013;92(11):1041-1047.

39. Eke PI, Dye BA, Wei L, et al. Prevalence of periodontitis in adults in the United States: 2009 and 2010. J Dent Res. 2012;91(10):914-920.

International Journal of COPD

\section{Publish your work in this journal}

The International Journal of COPD is an international, peer-reviewed journal of therapeutics and pharmacology focusing on concise rapid reporting of clinical studies and reviews in COPD. Special focus is given to the pathophysiological processes underlying the disease, intervention programs, patient focused education, and self management protocols.
Dovepress

This journal is indexed on PubMed Central, MedLine and CAS. The manuscript management system is completely online and includes a very quick and fair peer-review system, which is all easy to use. Visit $\mathrm{http}: / / \mathrm{www}$.dovepress.com/testimonials.php to read real quotes from published authors.

Submit your manuscript here: http://www.dovepress.com/international-journal-of-chronic-obstructive-pulmonary-disease-journal 